\title{
CASO CLINICO: ASPERGILOSIS NO INVASIVA EN PACIENTE VIH
}

\section{(Clinical report: Non invasive aspergillosis in a HIV patient)}

\author{
Rodrigo Cruz (1), Silvia Campos (2), \\ Elizabeth Barthel (3), Gonzalo Fernández (4)
}

(1) Cátedra de Micología U. de Valparaíso, Casilla 92V, Valparaíso Chile, email; rcruzchoappa@gmail.com. (2) Servicio de Medicina Hospital Eduardo Pereira, Valparaiso

(3) Infectología Hospital Carlos Van Buren (4) Servicio de Medicina Hospital de Peñablanca

Palabras clave: Asperguillus fumigatus, aspergilosis no invasiva. Key word: Asperguillus fumigatus non invasive aspergillosis.

\begin{abstract}
RESUMEN
Se reporta el caso clínico de un paciente con antecedentes de VIH/SIDA etapa C3, con TBC pulmonar tratada, con un absceso pulmonar antiguo y múltiples hospitalizaciones previas por un cuadro de varios meses de evolución, caracterizado por tos con expectoración purulenta, hemoptisis, fiebre y compromiso del estado general. Dentro del estudio destacaron 3 muestras de expectoración positivas para Aspergillus fumigatus, con estudio bacteriológico negativo y radiografia de torax sin cambios en relación a las tomadas con anterioridad. Con estos elementos, se diagnosticó una aspergilosis pulmonar no invasiva $y$, considerando su estado de inmunosupresión, las múltiples hospitalizaciones por este cuadro y la mala condición social del paciente, se decidió iniciar un tratamiento con Itraconazol, además de reiniciar tarapia antiretroviral. El paciente evolucionó favorablemente, con cultivos negativos de expectoración después de 3 meses de tratamiento.
\end{abstract}

\section{INTRODUCCION}

Los hongos pertenecientes al género Aspergillus son causa frecuente de infecciones tanto invasivas como no invasivas en pacientes inmunodeprimidos y/o con factores predisponentes para patógenos oportunistas. El

Recibido el 27 de Octubre 2007

Aceptado el 21 de Diciembre 2007

\section{ABSTRACT}

A clinic report of an HIV/SIDA patient in his C3 phase, bearing a previous TBC pulmonary disease already treated, together with an old pulmonary abscess as well as multiple previous hospitalizations due to symptoms meaning several months of evolution, and which were characterized by purulent expectoration cough, hemoptisis, fever and general health complications is discussed. Results of the study revealed that 3 samples of expectoration were positive for Aspergillus fumigatus, yielding negative for bacteriologic exam while thorax $x$-ray seemed unchanged as compared to those taken earlier. Based on this information, a non invasive pulmonary aspergillosis was diagnosed; besides considering his immunesuppression state, his multiple hospitalizations caused by these symptoms as well as the bad social condition of the patient, it was determined to treat him with Itraconazol together with a restart of a retroviral therapy. The patient had a favorable evolution and after a three-month treatment he showed negative cultures of expectoration.

principal órgano afectado es el pulmón y Aspergillus fumigatus corresponde a la especie más aislada en todas sus formas clínicas (Thomson et al., 1987; Pitt, 1994; Pontón, 2003; Cruz et al., 2005).

Las formas de presentación clínica no invasiva estan constituidas por la colonización traqueobronquial, la aspergilosis alérgica (alveolitis alérgica extrínseca y aspergilosis broncopulmonar alérgica) y el aspergiloma o 
bola fúngica. La colonización traqueal, de bronquios dilatados o de cavidades en pacientes con daño pulmonar crónico, sin invasión del parenquima pulmonar, es frecuente y generalmente subdiagnosticada (Carrasco, 2004).

Estudios ambientales han demostrado que a diario podemos inhalar cientos de conidios de $\boldsymbol{A}$. fumigatus dependiendo del ambiente donde nos desenvolvamos y está directamente relacionado con la cuantía de plantas y árboles presentes (Walsh \& Dixon, 1989; Goodley et al., 1994). Los conidios inhalados generalmente son eliminados por la inmunidad celular, sin embargo, en pacientes inmunodeprimidos o con alteración estructural de bronquios, alveolos o del parenquima pulmonar, pueden provocar invasión o colonización generando abundante sintomatología respiratoria crónica (tos, expectoración, hemoptisis y fiebre).

Del total de especies de Aspergillus conocidas, sólo unas 20 se han relacionado con patologías en el hombre, de estas las más importantes por frecuencia son: A. fumigatus, A. flavus, A. niger, A. nidulans (Emericella) y A. terreus (Herbrecht et al., 2004).

\section{CASO CLÍNICO}

Paciente masculino de 36 años de edad, con antecedentes de VIH/SIDA en control en hospital Carlos Van Buren (HCVB) desde el año 2000, con múltiples abandonos de la terapia antiretroviral (en febrero del 2007 con CD4 menor de 50), TBC pulmonar tratada en Hospital del Tórax de Santiago en 1996, daño hepático crónico secundario a alcoholismo intermitente. Debe destacarse sus condiciones precarias de vida, sin un lugar de residencia establecido, sin un trabajo formal y pernoctando en albergues de ayuda social. Además presenta antecedentes de múltiples hospitalizaciones tanto en

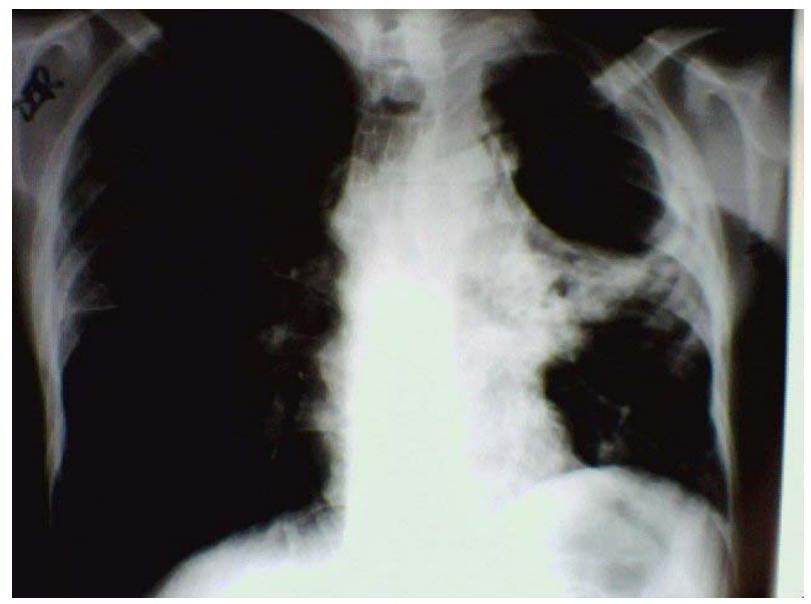

Figura 1. RX Tórax anteroposterior (16/4/06)
HCVB como en el Hospital Eduardo Pereira (HEP) desde el 2004:

- Absceso pulmonar izquierdo 5/10/05

- Varicela extensa 17/03/06

- Antrostomia por sinusitis el 6/6/06. No se encuentran los cultivos de este procedimiento.

- Ocho hospitalizaciones por cuadro de fiebre, calofríos, tos productiva purulenta, hemoptisis y CEG permanente. Todas con BK (-) y cultivo de Koch (-), con varios esquemas antimicrobianos en cada hospitalización y múltiples exámenes realizados en ambos hospitales: destacó eosinofilia de hasta 16\% en los hemogramas.

En la Tomografía axial computarizada (TAC) pulmonar del 08/07/2006 se describen imágenes cicatrizales probablemente de TBC como primera posibilidad, bula gigante en ápice pulmonar izquierdo. Imágenes descritas podrían ser reactivación y/o sobreinfección, con nódulos en mediastino probablemente adenopatías inflamatorias.

Durante su hospitalización en febrero del 2007 se realizaron:

- Fibrobroncoscopia: Secreción mucosa sin otras alteraciones. Con baciloscopia, Cultivo de Koch y en agar sabouraud negativos.

- Endoscopia digestiva alta: candidósis esofágica y hernia hiatal deslizante.

El 16/ 04/2007 consulta nuevamente en unidad de emergencia del HCVB por cuadro de un mes de evolución caracterizado por fiebre, tos productiva con hemoptisis y moderado compromiso del estado general, se toma radiografia de tórax (Figuras 1 y 2).

La radiografía muestra lesiones secuelares de TBC, con imagen bulosa en lobulo superior izquierdo y probable neumopatía intersticial, sin embargo, al compararla con la

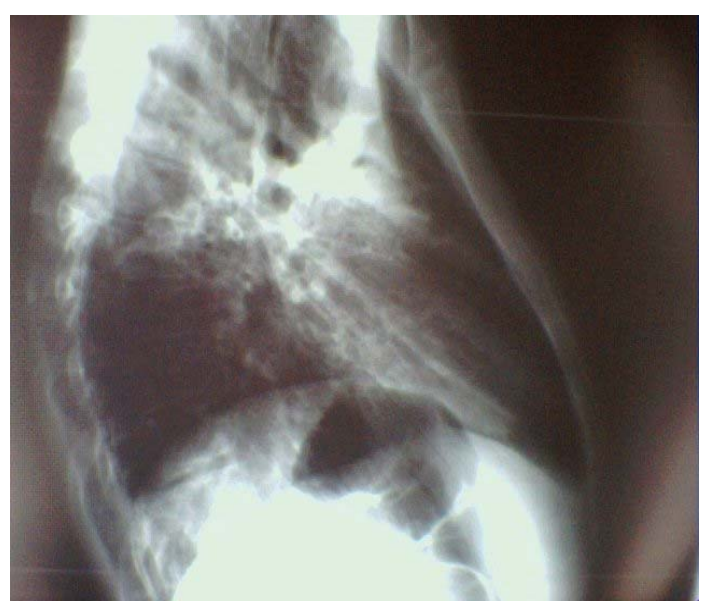

Figura 2. RX Tórax Proyección lateral 
radiografía de su hospitalización previa en HEP no se observan cambios significativos.

Dentro de los exámenes generales practicados durante su última hospitalización destacan: Rcto leuc: 3.100 cels. Eos: 8\%, PCR: 82,7 mg/L, Hcto: 24.4\%, LDH: 635, Albúmina: 2,8 g/ L, GGT: 163 U/L, FA: 538 U/L. Ecotomografia abdominal: hepatopatía difusa con signos sugerentes de daño hepático crónico e hipertensión portal, con ligero aumento difuso del páncreas sugerente de proceso inflamatorio y Esplenomegalia difusa.

De los exámenes microbiológicos destacaron:

- BK(2): negativas

- Hemocultivos: negativos

- Urocultivo: negativo

- Tinción con azul de toluidina de expectoración: negativo para Pneumocystis jirovecii

- Directo con KOH al 20\% de expectoración: escasas hifas hialinas con septos. Múltiples bacterias y algunas levaduras.

- Cultivo Sabouraud: desarrollo abundante de Aspergillus fumigatus. Se repitieron las muestras de expectoración para cultivo en tres ocasiones, con el mismo resultado anterior (Fig. 3).

Considerando lo prolongado del cuadro clínico, el daño pulmonar previo, la escasa variación de las radiografias en el tiempo y los cultivos positivos para $\boldsymbol{A}$. fumigatus en la expectoración, se planteó el diagnóstico de aspergilosis no invasiva y se inició tratamiento con Itraconazol $400 \mathrm{mg} /$ día, además de reinicio de terapia antiretroviral y traslado al Hospital de Peñablanca para supervisión del tratamiento y apoyo social. El paciente llevó correctamente el tratamiento (completó 12 semanas), sin reacciones adversas, sin fiebre, sin tos ni expectoración, con cultivos de expectoración negativos desde la segunda semana de tratamiento y LDH en sangre dentro de rangos normales.

Debido a su buena evolución clínica y su buena tolerancia al ejercicio el paciente decide fugarse de este último hospital sin volver a consultar, hasta el momento, en algún hospital de la región.

\section{Aspectos morfológicos}

Microscopía: la expectoración del paciente fue sembrada en placas con agar Sauborau, obteniéndose abundante aislamiento de Aspergillus fumigatus que en los sub-cultivos en agar Czapek (CZ) y Malta (AM) a $37^{\circ} \mathrm{C}$ por 7 días, desarrollaron colonias con diámetros de aproximadamente de $60 \mathrm{~mm}$ en AM y de $55 \mathrm{~mm}$ en CZ, de color verde azulado a grisáceo con reverso incoloro, de textura aterciopelada, planas. Cabezas conidiales predominantemente columnares, con conidióforos incoloros, grisáceos cerca del ápice, de pared lisa de 200-400 por 5-10 $\mu \mathrm{m}$, vesícula piriforme de 18-30 $\mu \mathrm{m}$ de diámetro. Fiálides

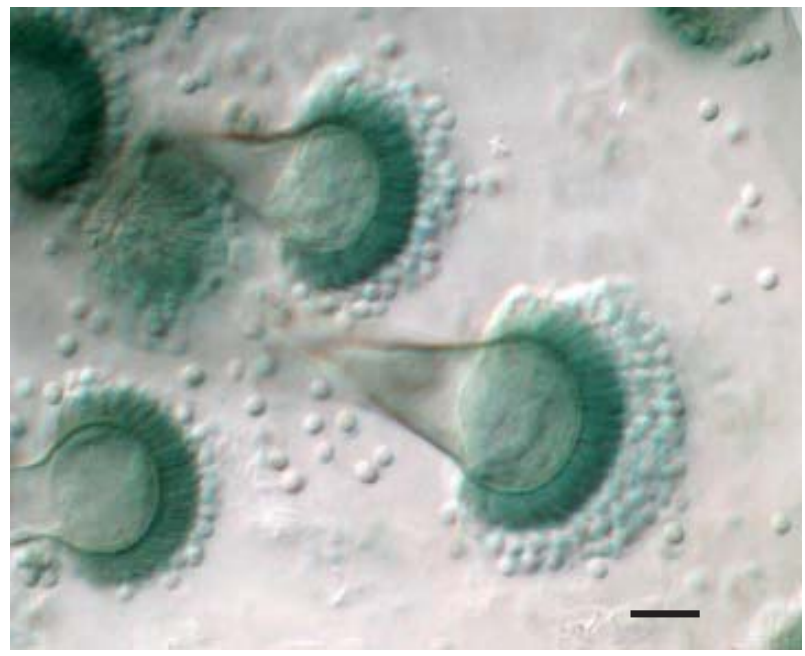

Figura 3. Aspergillus fumigatus. Conidióforos, fiálides $\mathrm{y}$ conidio. Barra $=10 \mu \mathrm{m}$

monoseriadas de 6-8 por 2-3 $\mu$ m que cubren de la mitad a los 2/3 superiores de la vesícula, paralelas entre ellas y siguiendo la dirección del eje del conidióforo. Conidios globosos, elipsoidales, lisos a finamente rugosos de 2-3 $\mu \mathrm{m}$ de diámetro.

\section{DISCUSION}

Las distintas especies de Aspergillus pueden colonizar las vías respiratorias en aquellos pacientes con alguna alteración de la estructura del arbol bronquial y/o pulmonar, en especial A. fumigatus, la especie aislada con mayor frecuencia, tanto en ambientes internos como en los externos (Oddo \& Thomson, 1990; Teh et al., 1995; Johnson et al., 1999; Sanchez, 2000).

La aspergilosis no invasiva endobronquial se manifiesta clinicamente por tos productiva crónica, a menudo con hemoptisis en pacientes con antecedentes previos de TBC, bronquiectasias, EPOC o sarcoidosis (Bennet, 2005).

En los pacientes con SIDA en etapa avanzada, el aislamiento de Aspergillus de un cultivo de expectoración obliga inmediatamente a descartar una probable infección invasiva; para esto es necesario realizar unaTAC pulmonar, fibrobroncospia con lavado alveolar o cepillado y toma de biopsias transbronquiales. Estas muestras deben ser enviadas para cultivos especiales al laboratorio para su identificación (Raper \& Fennel, 1965; Klich, 2002; Guzmán,2005) y a anatomía patológica para tinción de Gomori Grocot en el caso de las muestras de pulmón; con estos resultados podemos tener un acercamiento lo más próximo y rápido para iniciar un tratamiento precoz de las aspergilosis tanto no invasiva como en la invasiva. 
En el caso expuesto, el paciente es VIH positivo en etapa C3 con secuelas pulmonares debido a tuberculosis pulmonar antigua y un absceso pulmonar tratado en el año 2005. Su cuadro clínico actual fue la continuación de un cuadro crónico caracterizado por tos productiva persistente, fiebre y compromiso del estado general. Todas las muestras bacteriológicas tomadas resultaron negativas y la radiografía no mostró una masa fúngica en la caverna del lóbulo superior izquierdo ni la presencia de un proceso de condensación. De los tres cultivos de expectoración tomados, todos fueron positivos con abundantes colonias de A. fumigatus. Por este motivo y considerando la condición de inmusupresión del paciente, junto a las múltiples hospitalizaciones por esta causa, sumado a su condición social alterada se decidió iniciar un tratamiento con antifúngico y terapia antiretroviral y su traslado al Hospital Sanatorio de Peñablanca para completar tratamiento supervisado con apoyo social. La evolución clínica fue excelente; cedió la tos, la fiebre, su estado general mejoró considerablemente y subió de peso. En los controles de expectoración todas las muestras resultaron negativas para hongos, y en el último mes no se pudo efectuar este examen por falta de expectoración.

La mayoría de las publicaciones nacionales sobre aspergilosis están dirigidas a la presentación invasiva, sin embargo Yarzabal et al en 1974, publicaron una serie de 48 casos de aspergillosis, dentro de los cuales 25 fueron considerados no invasivas.

En los últimos años Carrasco et al. 1988 Carrasco, 2004, publican el perfil clínico y las complicaciones de la aspergillosis broncopulmonar alergica (ABPA), una de las formas más frecuentes y complicadas de tratar dentro de las no invasivas.

A nivel internacional también predominan las publicaciones sobre aspergillosis invasiva. (Henderson \& Chapman, 2004), dado principalmente por la gravedad de esta forma de la infección y por el aumento de los pacientes inmunodeprimidos susceptibles para cursar con una aspergilosis.

\section{REFERENCIAS}

Bennet, J. (2005). Aspergilosis. Harrison 16 edición. 2005. Capítulo Enfermedades Infecciosas.

Carrasco, E. (2004). Aspergilosis broncopulmonar alergica. Complicaciones poco usuales de la afección. Rev. Chil. Enf. Respir. 20:30-6

Carrasco, E.; Sepulveda, R.; Rojas, L.; Mendéz, P.; Vicherat, L.; Otero, M. (1998). Perfil clínico inmunológico de la aspergilosis broncoplulmonar alergica (ABPA). Enf. Resp. Cir. Torax. 4:7682
Cruz, R.; Barthel E.; Piontelli, E.; Fernandez, G. (2005). Reportes Clinicos: infección rinosinusal por Aspergillus flavus probada y probable infección pulmonar por Emericella nidulans en pacientes inmunocomprometidos. Boletin Micologico 20:109115

Goodley, J.M.; Clayton, Y.M. \& Hay, R.J. (1994). Environmental sampling for aspergilli during building construction on a hospital site. J. Hosp. Infect. 26:27-35

Guzmán, D.A.M. (2005). Importancia del laboratorio en el diagnóstico de las micósis invasoras. Rev. Chil. de Infect. 21:3947

Henderson, H \&; Chapman, S. (2004). Reese Betts. Primera edición. Capítulo Infecciones por Hongos, Actinomyces y Nocardia.

Herbrecht, R.; Denning, D. W.; Patterson, T.F.; Bennett, J.E.; Greene, R.E.; Ostermann, J. M.(2002). Voriconazol versus anphoptericin B for primary of invasive aspergillosis. New Eng. J. Med. 347:408-4

Johnson, T.E.; Casiano, R.; Kronish, J.E; Tse, D.T.; Meldrum, M.; Chang, W. (1999). Sino-orbital aspergillosis in acquired in immunodeficiency syndrome. Arch. Ophthalmol. 117:1-10

Klich, M. A. (2002). Identification of common Aspergillus species. CBS. Utrecht, The Netherlands

Oddo, D. \& Thomson, L. ( 1990). Micosis pulmonares. Algunos aspectos de su diagnóstico anatomopatológico y de laboratorio. Rev. Chil. de Inf. 7:197-207

Pitt, J.I. (1994). The current rol of Aspergillus and Penicillium in human and animal health. J. Med. Vet. Mycol. S1.17-32

Pontón J. (2003). Aspergilosis Invasora. Primera edición. Asociación Española de Micología.

Raper, K.B. \& Fennel, D.I. (1965). The genus Aspergillus. Baltimore, USA: Williams and Wilkins.

Sánchez, J. (2000). Prevención de la aspergilosis nosocomial. Rev. Iber .de Micol. 17:s:100-102

Teh, W.; Matti, B.S.; Marisiddaiah, H. \& Minamoto, G.Y.(1995). Aspergillus sinusitis in patient with AIDS. Clin. Inf. Dis. 21:529- 535

Thomson, L.; Oddo, D \& Retamal, C. (1987). Orientaciones clínicas y de laboratorio en micosis oportunistas. Rev. Chil. de Infect. 4:69-74

Yarzabal ,L.; Sepúlveda, R.; Retamal, C.; Salamanca, L. (1974). Pulmonary aspergillosis. Rev. Med. Chile 102:772-8

Walsh, T.J \& Dixon, D.N. (1989). Nosocomial aspergilosis: environmental microbiology, hospital epidemiology, diagnosis and treatment. Eur. J. Epideliology. 5:1616-1622 